\title{
ANALYSIS OF FACTORS AFFECTING CRASH SEVERITY OF PEDESTRIAN AND BICYCLE CRASHES INVOLVING VEHICLES AT INTERSECTIONS
}

\author{
Thesis \\ Submitted to \\ The School of Engineering of the \\ UNIVERSITY OF DAYTON
}

In Partial Fulfillment of the Requirements for

The Degree of

Master of Science in Civil Engineering

By

Abdulaziz Hebni Alshehri

Dayton, Ohio

December 2017

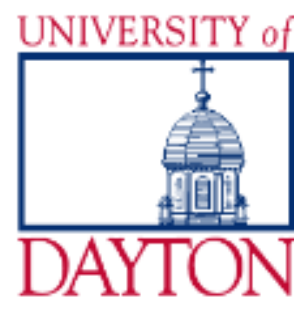




\section{ANALYSIS OF FACTORS AFFECTING CRASH SEVERITY OF PEDESTRIAN AND BICYCLE CRASHES INVOLVING VEHICLES AT INTERSECTIONS}

Name: Alshehri, Abdulaziz Hebni

\section{APPROVED BY:}

Deogratias Eustace, Ph.D., P.E., PTOE Advisory Committee Chairperson, Associate Professor, Department of Civil and Environmental Engineering and Engineering Mechanics
Peter Hovey, Ph.D. Committee Member, Associate Professor, Department of Mathematics

Paul Goodhue, P.E., PTOE

Committee Member, Traffic Engineering Key Services

Leader, LJB Group

Robert J. Wilkens, Ph.D., P.E. Associate Dean for Research \& Innovation Professor

School of Engineering
Eddy Rojas, Ph.D., M.A., P.E.

Dean, School of Engineering 


\begin{abstract}
ANALYSIS OF FACTORS AFFECTING CRASH SEVERITY OF PEDESTRIAN AND BICYCLE CRASHES INVOLVING VEHICLES AT INTERSECTIONS
\end{abstract}

Name: Alshehri, Abdulaziz Hebni

University of Dayton

Advisor: Dr. Deogratias, Eustace

Vulnerable road users (VRUs) such as pedestrians and bicyclists, also known as non-motorists, are vulnerable due to lack of protection in traffic. They are even more vulnerable at inteserctions due to increased exposure and conflicts with motor vehicles whose paths have to cross each other. The main objective of this thesis study was to determine factors that contribute significantly to the crash severity of intersection-related crashes involving motor vehicles and the vulnerable road users. When a motor vehicle crashes with a non-motorist road user, the non-motorist road user sustains the higher injury levels. Based on the objectives of this study, a three-year crash database from January 2013 to December 2015 acquired from the Ohio Department of Public Safety was utilized for this analysis. The logistic stepwise selection procedure was applied to estimate statistically significant predictor variables that contribute in increasing bicyclist and pedestrian-related crash severity levels. The logistic regression model identified five statistically significant 
predictor variables out of fourteen independent variables considered in the current research. The predictors that increase crash severity of crashes involving VRUs who collide with vehicles at intersections are pedestrian-related, road contour, gender, light condition, and unit in error. The other factors that are usually significant such as posted speed limits, alcohol-related, gender, age, etc., were not significant in the current study. However, speedrelated was not tested in the current study due to lack of enough cases where speeding was reported as contributing factor in the data set used. 


\section{ACKNOWLEDGMENTS}

First of all, I would like to thank the Almighty God for giving me this opportunity to finish my graduate education, especially this thesis. I would like to express my appreciation to my principal advisor, Dr. Deogratias Eustace who helped me all the way from start to finish in my thesis study. His door is always open to help me in any way, providing me his knowledge, and encouragement, which enabled me to achieve this accomplishment.

I will never forget Dr. Peter Hovey who helped me with the statistical part of my research. To be specific, he helped me with the analysis of data and be able get the essential results at the end. Without him, I don't know how I would have completed my work by utilizing an appropriate statistical analysis. His encouragement was a good source for me throughout my thesis study. In addition, I would like to thank Eng. Paul Goodhue for serving on my thesis committee, reviewing my thesis manuscript and providing me his advice to improve my thesis. His expertise was highly valuable in making my thesis successful.

I would like to thank my classmates and friends who gave me their time and efforts to overcome all of the obstacles I faced during my research. Big thanks to my friends who shared their thoughts and participated actively in this thesis and provided me with proofreading to improve my research thesis. They stood with me during difficult times and supported me, I simply say thanks a lot. 
Finally, I would like to express my profound gratitude to my family especially my parents and my wife. They supported and encouraged me in a different way especially me being abroad, far away from home, they never stopped praying for me and giving me their love through my education. Without them, I would have never reached where I'm today and I would not have done this research without them. 
TABLE OF CONTENTS

ACKNORACT

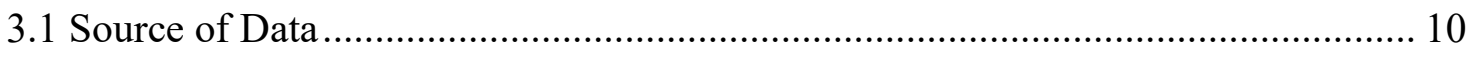

3.2 Description of Selected Variables for the study ........................................... 13

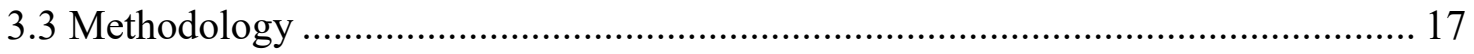

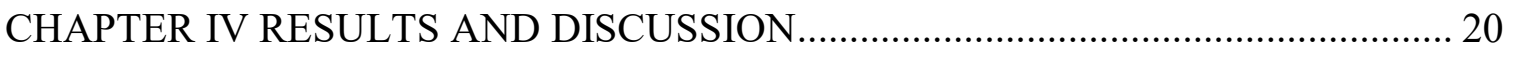

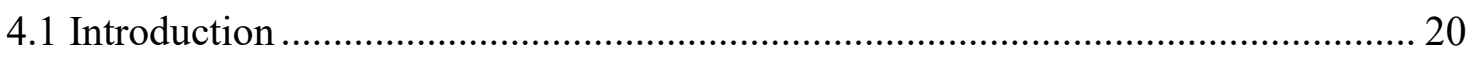

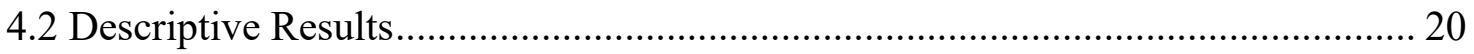

4.3 Binary Logistic Model Results of Crash Severity Analysis................................ 31

CHAPTER V CONCLUSIONS AND RECOMMENDATIONS ….............................. 36

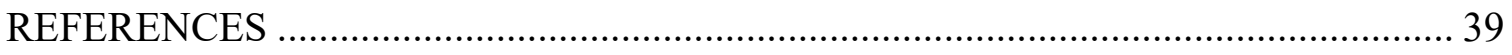




\section{LIST OF FIGURES}

Figure 3.1 The process of merging crash, unit and people record files................... 12

Figure 4.1 Percentage of Fatal and Injury Crashes by Road Contour ............................. 21

Figure 4.2 Percentage of Fatal and Injury Crashes by Alcohol Use ................................ 22

Figure 4.3 Percentage of Fatal and Injury Crashes by NMT Road User ......................... 23

Figure 4.4 Percentage of Fatal and Injury Crashes by Light Condition ........................... 24

Figure 4.5 Percentage of Fatal and Injury Crashes by Weather Condition ..................... 25

Figure 4.6 Percentage of Fatal and Injury Crashes by Age Group .................................. 26

Figure 4.7 Percentage of Fatal and Injury Crashes by Gender ....................................... 26

Figure 4.8 Percentage of Fatal and Injury Crashes by Road Condition............................ 27

Figure 4.9 Percentage of Fatal and Injury Crashes by Posted Speed Limit ...................... 28

Figure 4.10 Percentage of Fatal and Injury Crashes by Day of the Week ........................ 29

Figure 4.11 Percentage of Fatal and Injury Crashes by Location of Crash ..................... 30

Figure 4.12 Percentage of Fatal and Injury Crashes by Unit in Error ............................. 30

Figure 4.13 Odds Ratio with 90\% Wald Confidence Limits .......................................... 32 


\section{LIST OF TABLES}

Table 1.1: The Vulnerability of Road Users Compared Using 2015 Ohio Data ............... 3

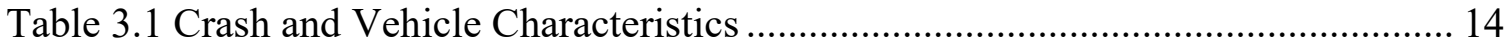

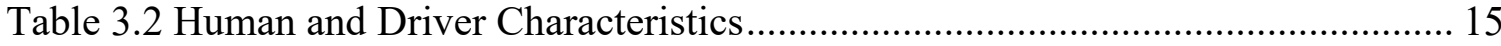

Table 3.3 Roadway and Environmental Characteristics ............................................ 16

Table 4.1 Detail of Significant Parameters from Binary Regression Model ................... 31 


\section{CHAPTER I}

INTRODUCTION

\subsection{Introduction}

Population growth as well as increased motorization have lead into 'concerns on traffic safety control at intersections. Intersections are one of the most crash-prone locations in any roadway network due to the complex nature of motor vehicle, pedestrian, bicyclist movements either turning, crossing or moving along and their paths crossing each other over a limited area. The main concern at intersections is for vulnerable road users (VRU's). We can define vulnerable road users by a number of ways such as the need of protection for those who are at more risk in a traffic stream, for example pedestrians and cyclists (which includes bicyclists and motor cyclists). In addition, we can also define vulnerable road users by their capability to perform the tasks, for example, the young are vulnerable to due to their inexperience and the elderly due to their deteriorated task capabilities.

At intersections, pedestrians and bicyclists are more vulnerable as their potential conflicts with motor vehicles increase due to their paths crisscrossing each other. When these conflicts lead into crashes, the majority of the injuries and fatalities occur to the VRUs. In order to protect these vulnerable road users against vehicles at intersections, it is important to know vulnerable road users crash-related factors that can help us to 
recommend effective countermeasures, which would help in reducing the problem (Stutts et al., 1996). According to the National Center for Statistics and Analysis (NCSA, 2017a), in 2015 there were 818 bicyclists killed in the United States, which was a $12.2 \%$ increase over those killed in 2014. Similarly, there were 5,376 pedestrians killed in the United States that accounted for a $10.0 \%$ increase when compared with pedestrian killed a year ago (NCSA, 2017b).

\subsection{Problem Statement}

When reviewing 2015 crash data, the rate of bicyclists killed in Ohio's public roads mirrors that of the national average. In the state of Ohio with a population of over 11.6 million, there 1,110 total traffic fatalities, 25 of which were bicyclists that accounts for $2.3 \%$ of total traffic fatalities and this rate is similar to that of the United States' average (NCSA, 2017a). In the case of pedestrians, there 118 deaths in Ohio, which accounts for 10.5\% of total traffic fatalities in the state, which was lower of the national average of $15.3 \%$ (NCSA, 2017b).

The Ohio Department of Public Safety (ODPS) annually publishes the Ohio traffic crash facts. Table 1 depicts some of crash records taken from the 2015 data (ODPS, 2016). These data clearly show that the so-called vulnerable road users have higher percent fatality-to-injury ratios when involved in traffic crashes due to lack of protection. Pedestrians have the highest percent fatality-to-injury ratio of 4.7 , followed by bicyclists with 2.0. The lower percent fatality-to-injury ratios for drivers and passengers reflect the good protection they receive from their vehicle bodies when involved in traffic crashes. 
Table 1.1: The Vulnerability of Road Users Compared Using 2015 Ohio Data

\begin{tabular}{|c|c|c|c|}
\hline Road User & Killed & Injured & Percent Fatality-to-Injury \\
\hline Bicyclists & 25 & 1,263 & 2.0 \\
\hline Drivers & 796 & 76,479 & 1.0 \\
\hline Passengers & 196 & 29,404 & 0.7 \\
\hline Pedestrians & 118 & 2,511 & 4.7 \\
\hline
\end{tabular}

\subsection{Objective of Study}

The main objective of this study was to identify the significant factors that affect the crash severity of pedestrian and bicycle crashes involving motor vehicles at intersections. The aim of this research study was to investigate the significant predictor factors of crash severity, which also affect the injuries sustained by pedestrians and bicyclists when they get involved in traffic crashes at intersections by examining factors such as environmental factors, traffic factors, road geometry, and driver factors in Ohio. From these results of identified significant factors, the current study attempts to propose countermeasures that may help in reducing injuries of these vulnerable road users.

\subsection{Organization of the Thesis}

This thesis consists of five main chapters. The first chapter introduces the topic, the extent of the problem and the objectives of the study. The second chapter presents the 
literature review on the injury and crash severity of pedestrians and bicyclists and the third chapter describes the methodology in general including data description and the statistical methodology used in analyzing the data. The fourth chapter presents the results and discussion of the results; and the fifth chapter provides a summary and conclusion of the research findings. 


\section{CHAPTER II}

\section{LITERATURE REVIEW}

Over the years, many studies have been conducted to analyze factors affecting crash frequency and injury and/or crash severity at intersections. Some vehicle-related, roadwayrelated, traffic-related, environmental-related, and human-related characteristics have been associated with pedestrian and bicycle crashes at intersections. Identified significant factors include vehicle type, vehicle speed, and vehicle-moving direction at intersections. In this regard, a study by Anderson et al. (1997) report that reduced posted speed limits are associated with reduced fatal pedestrian crashes. Posted speed limit may be a good surrogate measure of average vehicle speed on a roadway segment. In addition, a study by Lefler and Gabler (2004) found that pedestrians have a two to three times greater likelihood of death when struck by light trucks and vans compared to when struck by cars. At intersections, turning vehicles are more likely to strike pedestrians as drivers often fail to yield the right-of-way to pedestrians (Preusser et al., 2003).

Lee and Abdel-Aty (2005) illustrate that demographic factors of both pedestrians and drivers, road geometry, traffic and environmental factors significantly affect injury severity of pedestrians involved in crashes with vehicles that occur at intersections. They used pedestrian crash data from Florida for the years 1999-2002. They employed an ordered probit model in their pursuit to determine factors affecting pedestrian injury severity. 
Specifically, they found that pedestrian injury severity increased if a pedestrian struck in the crash was older or intoxicated, if the vehicle involved was traveling at high speed or if it was larger than a passenger car. In addition, the pedestrian's injury severity was higher if the crash happened during adverse weather or dark lighted environment, which may have affected the driver and pedestrian visions and reaction times.

Zajac and Ivan (2003) studied factors influencing injury severity of pedestrians struck by motor vehicles while attempting to cross two-lane highways not controlled by stop signs or signals. They utilized ordered probit model to evaluate various factors on injury severity of rural Connecticut pedestrians. They found that variables that significantly influenced pedestrian injury severity included clear roadway width (lane widths and shoulders), vehicle type, driver and pedestrian alcohol impairment, and pedestrian age 65 years or older. In addition, in terms of area type, they found that village, downtown fringe, and low-density residential area generally experienced higher pedestrian injury severity compared to downtown, compact residential, and medium- and low-density commercial areas

Schepers et al. (2011) studied road factors of bicycle-motor vehicle crashes at unsginalized priority intersections in the Netherlands. In their study, they included 540 intersections where police recorded 339 failure-to-yield crashes with bicyclists in four years. They conclude that the characteristics of priority intersection design affect bicyclist safety and bicycle crossings are safest when raised and deflected 2-5 $\mathrm{m}(6.6-16.4 \mathrm{ft})$ from the main lanes and more bicycle-motor vehicle crashes occur at well-marked bicycle crossings. 
The study by Herslund and Jørgensen (2003) conducted in Denmark reveal that the majority of motor vehicle-bicycle crashes occur at intersections. They are mainly due to lack of focus from drivers while attempting to turn left for bicyclists approaching at intersection.

Retting et al. (2002) performed field evaluation of two methods for restricting rightturn-on red (RTOR) to promote pedestrian safety. Presence of vehicles and turning on noright-turn-on-red has increased the risk of pedestrians who in essence have the right of way to cross safely. They conclude that the first method with traffic signs prohibiting RTOR at specific times were more effective at increasing driver compliance with stop lines, reducing the number of drivers turning right on red without stopping, and reducing the number of pedestrians yielding right of way to turning vehicles. The second method with signs allowing drivers with the option to turn right on red based on whether pedestrians were present proved ineffective.

A study conducted in Victoria, Australia by Chen et al. (2012) that analyzed risk factors affecting the severity of intersection crashes reveal that intersection crashes involving pedestrian are more likely to result into fatal outcomes. Their study just reflect the vulnerability nature of pedestrians at intersections when exposed to motor vehicle crashes.

A study by Sisiopiku and Akin, (2003) in Michigan near the campus of Michigan State University reveal the main reasons for pedestrians to cross the street without following the designated walking signal. The university students participated in this study, and the results show that there were varieties of reasons for not to obey the walking signal, but the main reason is being in a hurry and save time. In addition, the presence of attractive 
places and huge crossing areas make pedestrians to cross in the middle of the street. The phrase right-of-way has a mixed misconception among road users that could increase the risk of motor vehicle-pedestrian crashes at intersections (Sisiopiku and Akin, 2003).

A study by Moore et al. (2011) studied bicyclist injury severity due to motor vehicle crashes at intersections and non-intersection locations utilizing data from the state of Ohio. They argue that some of the factors affecting bicyclist injury severity at intersection and non-intersection locations are essentially different and thus they developed different models to estimate impacts of various factors on bicyclist severity at both types of locations in order to avoid biased or inconsistent estimates. Their study conclude that for intersection crashes, factors such as not wearing helmet, being under influence of alcohol, being struck by a van, bicycle being struck on the side, horizontal curves with grades increase the injury severity of bicyclist.

A study by Kim et al. (2007) analyzed bicyclist injury severities in bicycle-motor vehicle crashes using 1997-2002 police-reported crash data from North Carolina. Their study report that adverse weather, darkness without streetlights, intoxication, head-on collisions, and speeding involvement.

Eluru et al. (2008) developed a mixed generalized ordered response model to examine pedestrian and bicyclist-injury severity levels in traffic crashes using data from the General Estimates System (GES) database. They argue that general patterns and relative magnitude of elasticity effects of injury severity determinants for pedestrians and bicyclists are similar and thus defend their non-motorist combined model of pedestrians and bicyclists. Their study conclude that significant factors that increase the non-motorist's 
injury severity include age of individual (older persons), posted speed limit (higher speeds), and time-of-day (when it is dark). 


\section{CHAPTER III}

\section{METHODOLOGY AND DATA COLLECTION}

\subsection{Source of Data}

In this study, traffic crash data for three years, from 2013 through 2015, were downloaded from the Ohio Department of Public Safety (ODPS) website. The ODPS traffic crash data are organized into four related files with crash data compiled together by calendar year. The four files are crash records, unit records, people records, and ODOT records. Each of these files contains a variable known as DOCNO, which is an important variable that relates records in all four files to their respective crash incidents, that is, each record that share the same crash incident have the same DOCNO. The unit records file and people records file contain an additional variable called UNITNO, which together with the DOCNO they relate all people involved in traffic crashes to the correct vehicles they were traveling in and their specific crash incidents they were involved. Therefore, these two very important variables are used to combine the four files together into one file by properly linking all related records together.

The manipulation and merging of the four related files mentioned above are be briefly explained as follows: 
a) The crash records file contains information specific to each crash incident. Information recorded include crash severity, vehicle in error, date of crash, time of crash, name of city, village or township where the crash occurred, FIPS place code, crash location, type of road, if alcohol, drug, or speed were involved, etc.

b) The unit records file contains information on each unit/vehicle involved in that crash incident recorded in the crash records file. Information recorded in this file includes unit type (e.g., motor vehicle, motorcycle, bicycle, pedestrian, etc.), vehicle defects, point of impact, number of occupants in the unit, most damaged area, posted speed limit, pre-crash actions, etc.

c) The people records file contains information on each person involved in each crash event with the exception of hit-and-run cases where information is always not available. Information recorded in this file includes person type (e.g., driver, occupant, or pedestrian), age, gender, severity of injury sustained by an individual, safety equipment used, etc.

d) The ODOT records file contains information such as county code, route type, latitude, longitude, crash type, etc.

Crash records, unit records, and people records files contained variables needed to achieve the objectives of the study. The merging of these files into one file was accomplished by using a single-to-many-merging technique in SPSS software (version 22). The crash records and unit records were joined together by the common variable DOCNO to create a crash-unit file. The joint crash-unit file was merged with their corresponding people records by using the two common variables DOCNO and UNITNO to create a joint crash-unit-people file for each year. After that, the joint crash-unit-people files for five 
calendar years were combined together to create a dataset of traffic crash data from January 2013 to December 2015. Figure 3.1 shows the crash data merging process.

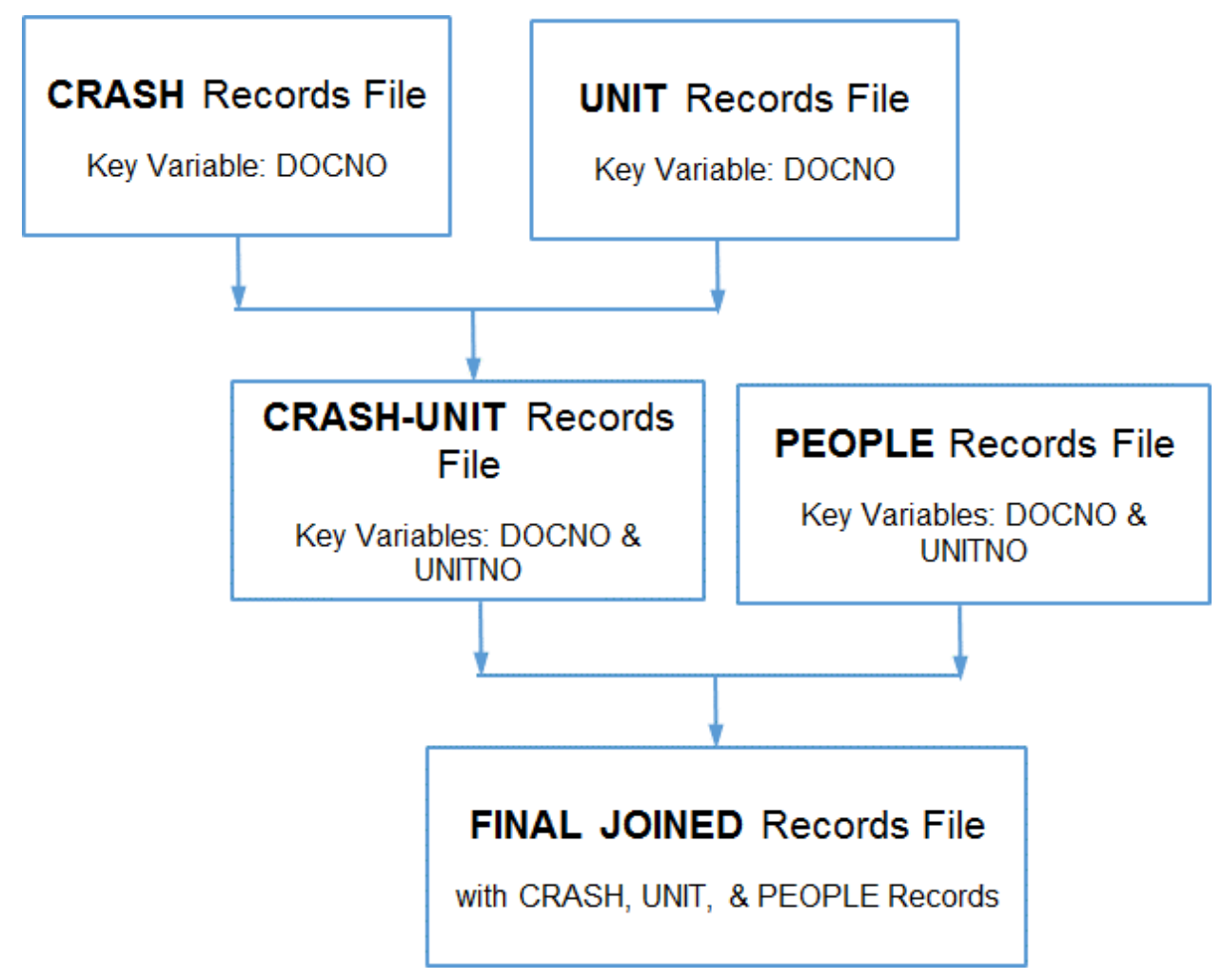

Figure 3.1 The process of merging crash, unit and people record files

The final merged file containing all information we need about the crashes that occurred in Ohio from January 1, 2013 to December 31, 2015 was used to create the pedestrian and bicycle only related crash dataset. Variables TYPE-OF_UNIT and PRECRASH_ACTIONS, and INTERSECTION-RELATED were used to sort out crash records that involved bicycle and pedestrian (bicycle-related and pedestrian-related subgroups) and motor vehicles at intersections. The final file that contained only crashes that occurred at intersections where bicycles and pedestrians were struck by motor vehicles has 4,019 
records where $2,138(53.2 \%)$ of them were pedestrian-related crashes and 1,881 (46.8\%) were bicycle-related crashes.

\subsection{Description of Selected Variables for the study}

The variables of interest to intersection-related traffic crashes that involved bicycles and pedestrians who were struck by motor vehicles that occurred on Ohio's public roads and streets from 2013-2015 after deleting missing and incomplete records are shown in Tables 3.1 through 3.3. The three tables describe the crash and vehicles characteristics, human/driver characteristics, and roadway/environmental characteristics. Table 3.1 shows variables pertaining to crash and vehicle characteristics. Variable crash severity, which is normally divided into three levels, that is, fatal (F), injury (I), and property damage only (PDO) was reduced into two levels, fatal/injury (F\&I) and property damage only (PDO). Fatal and injury levels were combined together because fatal crashes were only $1.9 \%$ and injury crashes were $90.2 \%$. Since these crashes involved VRUs, the fatal/injury crash category contained the majority of the data with $92.1 \%$ of the total 4,019 records and property damage only was $7.9 \%$. In term of posted speed limit, $30.9 \%$ of the crashes occurred on roads with $25 \mathrm{mph}$ posted speed limits or lower, $25.9 \%$ occurred on roads with posted speed limits higher than $25 \mathrm{mph}$, and $43.2 \%$ were unknown (not recorded in the database). In term of location, urban areas accounted for $88.1 \%$ of the crashes and $11.9 \%$ occurred in rural settings. 
Table 3.1 Crash and Vehicle Characteristics

\begin{tabular}{|c|c|c|c|c|}
\hline Variable & Code & Description & Frequency & Percent (\%) \\
\hline \multirow{3}{*}{ Crash severity } & 0 & PDO & 316 & 7.9 \\
\cline { 2 - 5 } & 1 & Fatal/Injury & 3703 & 92.1 \\
\cline { 2 - 5 } & & Total & 4019 & 100 \\
\hline \multirow{4}{*}{ Posted Speed } & 0 & $<=25$ & 1242 & 30.9 \\
\cline { 2 - 5 } & 1 & $>25$ & 1040 & 25.9 \\
\cline { 2 - 5 } & 2 & Unknown & 1737 & 43.2 \\
\cline { 2 - 5 } & & Total & 4019 & 100 \\
\hline \multirow{3}{*}{ Location } & 0 & Urban & 3540 & 88.1 \\
\cline { 2 - 5 } & 1 & Rural & 479 & 11.9 \\
\cline { 2 - 5 } & & Total & 4019 & 100 \\
\hline \multirow{3}{*}{ Unit in Error } & 0 & No & 2432 & 60.5 \\
\cline { 2 - 5 } & 1 & Yes & 1587 & 39.5 \\
\cline { 2 - 5 } & & Total & 4019 & 100 \\
\hline
\end{tabular}

Table 3.2 shows variables related to human and driver characteristics. Males make up $65.3 \%$ of the people involved while $34.7 \%$ were females. Ages of people involved were divided into four age groups. People younger than 25 years old constituted $46.1 \%$ and $10.0 \%$ of involved road users aged between 25 and 30 years old. While $38.2 \%$ were aged between 31 and 64 years old, seniors (65+ years old) made up 5.7\%. Alcohol-related crashes accounted for a small portion of crashes, that is, it was involved in only $4.1 \%$ of all crashes. In terms of crash type, i.e., type of non-motorist (NMT) involved in the crash, bicycles accounted for $46.8 \%$ of the data and $53.2 \%$ were pedestrians. 
Table 3.2 Human and Driver Characteristics

\begin{tabular}{|c|c|c|c|c|}
\hline Variable & Code & Description & Frequency & Percent (\%) \\
\hline \multirow{3}{*}{ Alcohol-related } & 0 & No & 3853 & 95.9 \\
\cline { 2 - 5 } & 1 & Yes & 166 & 4.1 \\
\cline { 2 - 5 } & & Total & 4019 & 100 \\
\hline \multirow{3}{*}{$\begin{array}{c}\text { Pedestrian- } \\
\text { related }\end{array}$} & 0 & No & 1881 & 46.8 \\
\cline { 2 - 5 } & 1 & Yes & 2138 & 53.2 \\
\hline \multirow{3}{*}{ Gender } & & Total & 4019 & 100 \\
\cline { 2 - 5 } & 1 & Female & 1395 & 34.7 \\
\cline { 2 - 5 } & & Male & 2624 & 65.3 \\
\hline \multirow{4}{*}{ Age groups } & 0 & $<25$ & 4019 & 100 \\
\cline { 2 - 5 } & 1 & $25-30$ & 401 & 46.1 \\
\cline { 2 - 5 } & 2 & $31-64$ & 1534 & 38.0 \\
\cline { 2 - 5 } & 3 & $65+$ & 231 & 5.7 \\
\cline { 2 - 5 } & & Total & 4019 & 100 \\
\hline
\end{tabular}

Table 3.3 shows variables pertaining to roadway and environmental characteristics. Road contour levels were reduced into two levels, that is, straight and level locations in one category and straight grade/curve level/curve grade into the other category. About $85.6 \%$ of the crashes occurred on intersections on level and straight roads while $14.4 \%$ of them either occurred on straight curved, curved level, or curved graded roads. In terms of light condition, almost two-thirds of the crashes occurred during daylight condition (69.4\%) while only $30.6 \%$ of them occurred during nighttime. When it comes to the weather condition, $64.3 \%$ of the crashes occurred when the weather was clear, $22.9 \%$ during cloudy weather and $12.8 \%$ of the crashes occurred during rain, fog, snow, or wind conditions. For road condition, $81.7 \%$ of the crashes occurred on dry surfaces and $18.3 \%$ occurred when the surface was wet, with running water, or with snow/ice. The majority of the crashes occurred on undivided roadways $(92.1 \%)$ while only $7.9 \%$ took place on divided roadways. The time of crash was divided into two major categories, that is, daytime and nighttime. 
While $77.4 \%$ of the crashes occurred during daytime, $22.6 \%$ occurred during nighttime. In addition, $79.8 \%$ occurred during weekdays and $20.2 \%$ occurred on weekends.

Table 3.3 Roadway and Environmental Characteristics

\begin{tabular}{|c|c|c|c|c|}
\hline Variable & Code & Description & Frequency & Percent $(\%)$ \\
\hline \multirow{3}{*}{$\begin{array}{l}\text { Road } \\
\text { Contour }\end{array}$} & 0 & Straight Level & 3442 & 85.6 \\
\hline & 1 & $\begin{array}{l}\text { Straight Grade/Curve } \\
\text { Level/Curve Grade }\end{array}$ & 577 & 14.4 \\
\hline & & Total & 4019 & 100 \\
\hline \multirow{3}{*}{$\begin{array}{l}\text { Light } \\
\text { Condition }\end{array}$} & 0 & Daylight & 2790 & 69.4 \\
\hline & 1 & Nighttime & 1229 & 30.6 \\
\hline & & Total & 4019 & 100 \\
\hline \multirow{4}{*}{$\begin{array}{l}\text { Weather } \\
\text { condition }\end{array}$} & 0 & Clear & 2584 & 64.3 \\
\hline & 1 & Cloudy & 920 & 22.9 \\
\hline & 2 & Rain/Fog/Snow/Wind/Other & 515 & 12.8 \\
\hline & & Total & 4019 & 100 \\
\hline \multirow{3}{*}{$\begin{array}{c}\text { Road } \\
\text { Condition }\end{array}$} & 0 & Dry & 3285 & 81.7 \\
\hline & 1 & Wet/Water/snow/ice & 734 & 18.3 \\
\hline & & Total & 4019 & 100 \\
\hline \multirow{3}{*}{$\begin{array}{l}\text { Road } \\
\text { Type }\end{array}$} & 0 & Divided & 319 & 7.9 \\
\hline & 1 & Undivided & 3700 & 92.1 \\
\hline & & Total & 4019 & 100 \\
\hline \multirow{3}{*}{$\begin{array}{l}\text { Time of } \\
\text { Crash }\end{array}$} & 0 & Daytime & 3111 & 77.4 \\
\hline & 1 & Nighttime & 908 & 22.6 \\
\hline & & Total & 4019 & 100 \\
\hline \multirow{3}{*}{$\begin{array}{l}\text { Day of } \\
\text { Week }\end{array}$} & 0 & Weekends & 811 & 20.2 \\
\hline & 1 & Weekdays & 3208 & 79.8 \\
\hline & & Total & 4019 & 100 \\
\hline
\end{tabular}




\subsection{Methodology}

This section discusses the research methodology used in this study to accomplish the objectives of the study. In the current study, crash severity was the response variable we are attempting to model in terms of other predictor variables presented in Tables 3.1 through 3.3. A binary logistic regression model was developed to analyze the crash severity data. When examining the crash severity variable, which originally has three levels of severity, i.e., property damage only (PDO), injury, and fatal injury, it became logical to reduce them into two levels. Originally, the crash data comprised $8.1 \%$ of PDO crashes, $90.0 \%$ of injury crashes (I), and $1.9 \%$ of fatal injury crashes (F). On a modeling viewpoint, it was logical to combine injury and fatal injury crashes together into one category (F\&I) and as a result, the crash severity dependent variable became a binary variable. Eventually, this is the basis to decide on using binary logistic regression as the model procedure. Subsequently, the objective of the current study was to determine significant factors affecting crash severity of bicyclists and pedestrians when struck by motor vehicles at intersections.

Binary logistic regression model is typically used in modeling the relationship between a categorical response variable (i.e., with two categories or levels) and a group of predictor variables. The logistic regression model of predicting the crash severity of a nonmotorist (with two possible outcomes of severity, PDO and F\&I) using a number of selected predictor variables was developed. With a binary logistic regression, the probability of success falls between 0 and 1 (coded as $0=$ PDO crashes and $1=$ F\&I crashes) for all possible $X$ values is basically an ordinary regression by maximum likelihood method using a logit as the response variable and described by Equation 1 (Agresti, 2007): 
$\operatorname{logit}(p)=\log \left(\frac{P}{1-P}\right)=\beta_{0}+\sum_{i=1}^{n} \beta_{i} X_{i}$

Where:

$$
\begin{aligned}
& p=\text { probability for }(Y=1) \text {, i.e., in this case if a VRU's crash becomes an injury or } \\
& \text { fatal crash } \\
& \beta_{0}=\text { model constant term } \\
& \beta_{i}=\text { regression coefficient for a predictor variable, } X_{i} \text {, } \\
& X_{i}=\text { predictor variable } i \\
& n=\text { number of explanatory variables in the model }
\end{aligned}
$$

By exponentiation of the regression coefficient of the predictor variable provides a multiplicative effect of that predictor on the odds, keeping other predictor variables constant. This manipulation leads into the equation to solve for the probability, $p$, in the logit model of Equation 1 and it is usually computed as shown in Equation 2:

$$
p=\frac{\exp \left(\beta_{0}+\sum_{i=1}^{n} \beta_{i} X_{i}\right)}{1+\exp \left(\beta_{0}+\sum_{i=1}^{n} \beta_{i} X_{i}\right)}
$$

The Wald or likelihood-ratio tests are usually used to test the significance (inference) of regression models. The Wald test in the framework of logistic regression model is used to decide whether a certain predictor variable $X_{i}$ is significant or not. If the 
predictor variable is significant, it simply rejects the null hypothesis of its corresponding regression coefficient being zero, i.e., $\mathrm{H}_{\mathrm{o}}: \beta_{i}=0$, and thus the alternative hypothesis is accepted; i.e., $\mathrm{H}_{\mathrm{a}}: \beta_{i} \neq 0$ The likelihood-ratio test provides similar evidence, but it compares two models, by testing that extra predictor parameters in the complete model equal zero (Agrest, 2007). 


\section{CHAPTER IV}

\section{RESULTS AND DISCUSSION}

\subsection{Introduction}

A number of human/behavioral, geometric, environmental, and traffic factors, considered to have an impact on crash severity, were analyzed by using binary logistic regression model, a suitable statistical modeling procedure suitable in analyzing ordered categorical response with only two levels (categories). The aim was to determine the most significant factors affecting crash severity of pedestrians and bicyclists involved in crashes with motor vehicles at intersections. Fourteen predictor variables were selected (refer to Tables 3.1 through 3.3) to analyze the crash severity. The stepwise logistic procedure in the SAS software release 9.4 was used in this study. Predictor variables were tested at a $90 \%$ significance level. The first part of this chapter presents the descriptive results based on the data analyzed in this study; the second part discusses the results of significant factors of the binary logistic regression model.

\subsection{Descriptive Results}

Examining closely the characteristics of crash data can provide a decent inference at some underlying aspects of the motor vehicle traffic crashes and therefore can assist the analyst in devising possible safety countermeasures. Data used in the current study as 
described in Chapter 3, show some characteristics of the variables used to predict crash severity of bicyclists and pedestrians. The description results discussed in this section are based on these data.

Figure 4.1 shows the relationship between crash severity sustained by pedestrians and bicyclists when struck by motor vehicles at intersections and road contour. The results show that $92 \%$ of the crashes that occurred at intersections on straight and level roads resulted into either fatalities or injuries while on roads with curves and grades, the rate was $93 \%$. This result is rather expected as curves and grades may reduce the sight distance and reaction time for both the non-motorist road user (VRU) and the motorist at the intersection to be able to react and evade the eminent crash or slow down and hence with a chance to reduce the crash/injury severity.

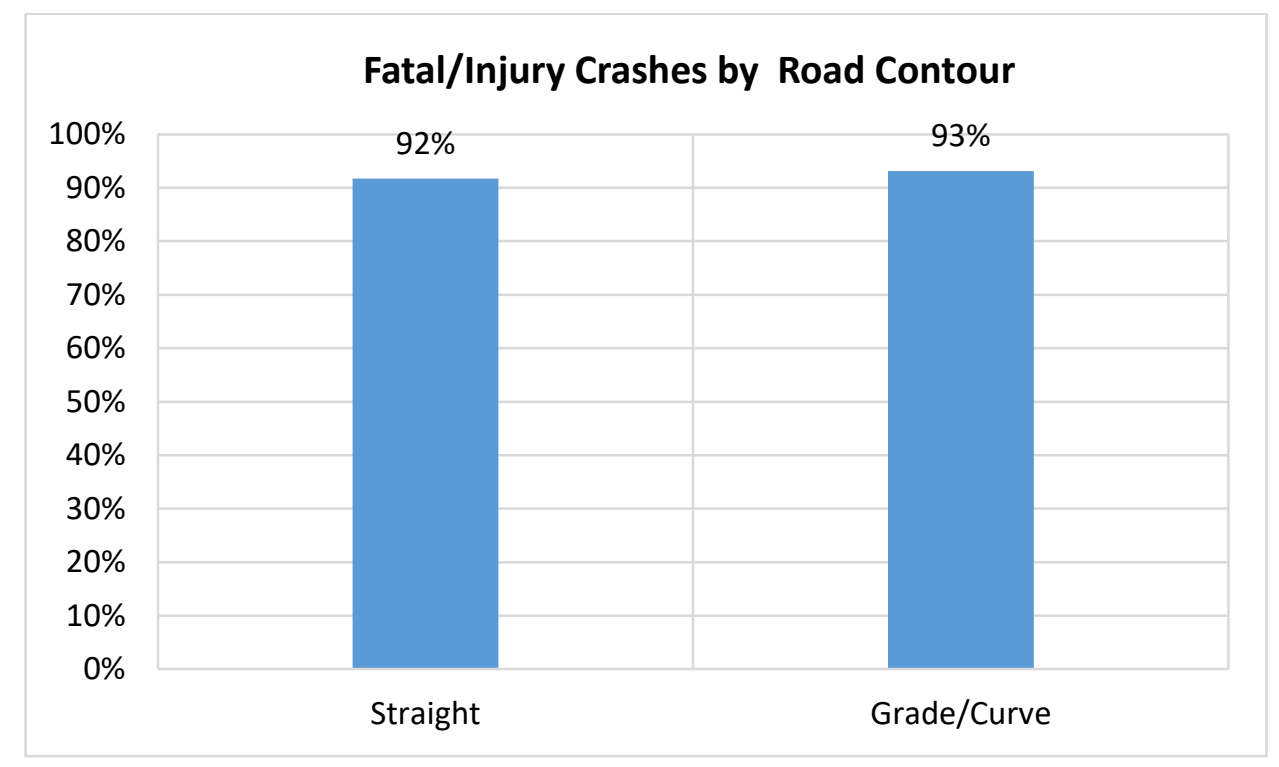

Figure 4.1 Percentage of Fatal and Injury Crashes by Road Contour 
Figure 4.2 shows the effect of the influence of alcohol use to the rate of fatal and injury crashes. When alcohol use was involved in the pedestrian- and bicycle-related crashes, the rate of fatal or injury (F\&I) crashes was $92 \%$ for both situations when alcohol impairment was involved and when it was not involved. This is not a typical result when compared to other studies previously conducted using Ohio crash data. For example, for a study on run-off-road (ROR) crashes, the rates were $49.5 \%$ and $34.6 \%$ for alcohol involved crashes and not involved crashes, respectively (Almutairi, 2013) and for a study on large trucks-related crashes; the rates were 52.5\% versus 20.7\% (Alqahtani, 2016). In addition, either way, you can note higher rates for VRUs (their F\&I percentages in the 90's) while for motor vehicles (ROR crashes and truck-related crashes) their F\&I rates are much lower, which signifies the heightened dangers non-motorists face in traffic crashes.

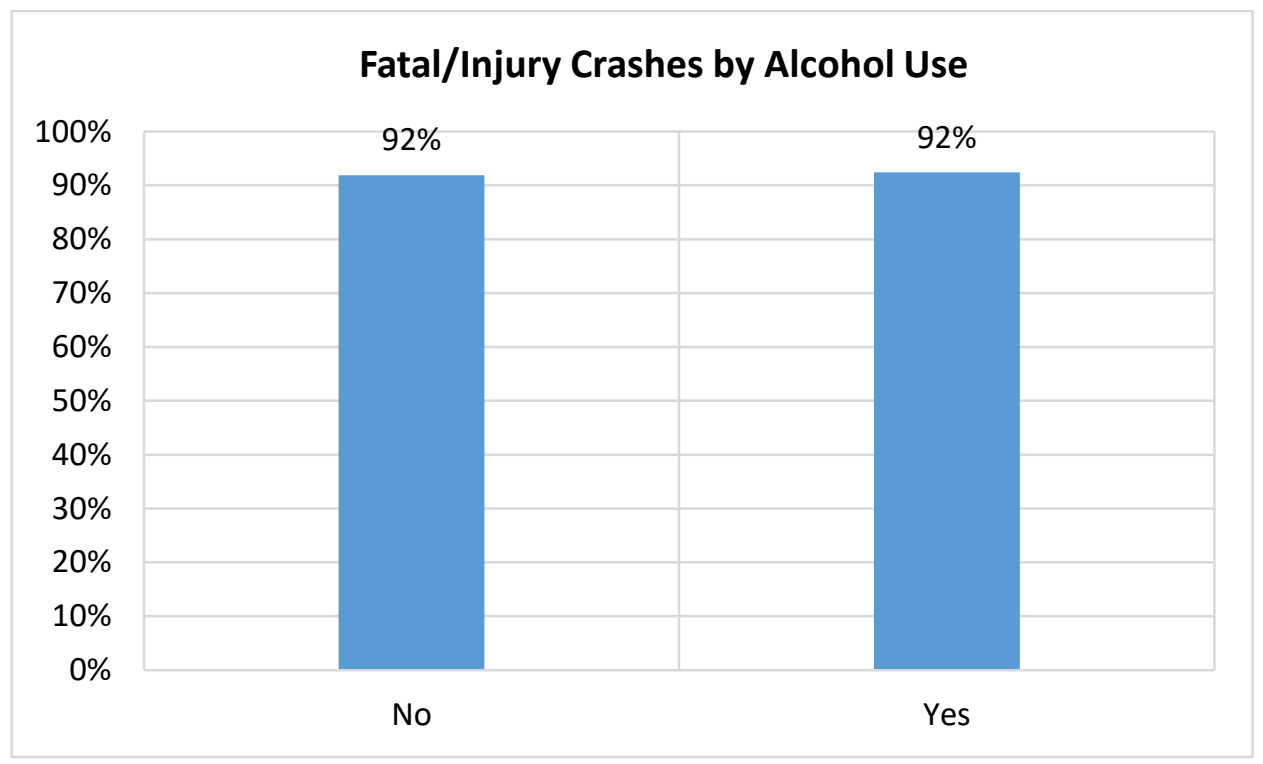

Figure 4.2 Percentage of Fatal and Injury Crashes by Alcohol Use

Figure 4.3 shows the percentage of pedestrian and bicycle crashes that were classified as fatal or injury $(\mathrm{F} \& \mathrm{I})$ crashes. Although both of them have relatively high 
percentages of $\mathrm{F} \& \mathrm{I}$ crashes, but pedestrians sustained a much higher percentage of $\mathrm{F} \& \mathrm{I}$ crashes (96\%) than bicyclists with an $88 \%$ of F\&I crashes. This indicates that even if both bicyclists and pedestrians are termed as non-motorists (NMTs) and vulnerable road users (VRUs), but pedestrians are more vulnerable due to completely lacking any kind of protection. Although bicycles may also be poor protectors of the road users, but they seem to provide some protection compared to pedestrians.

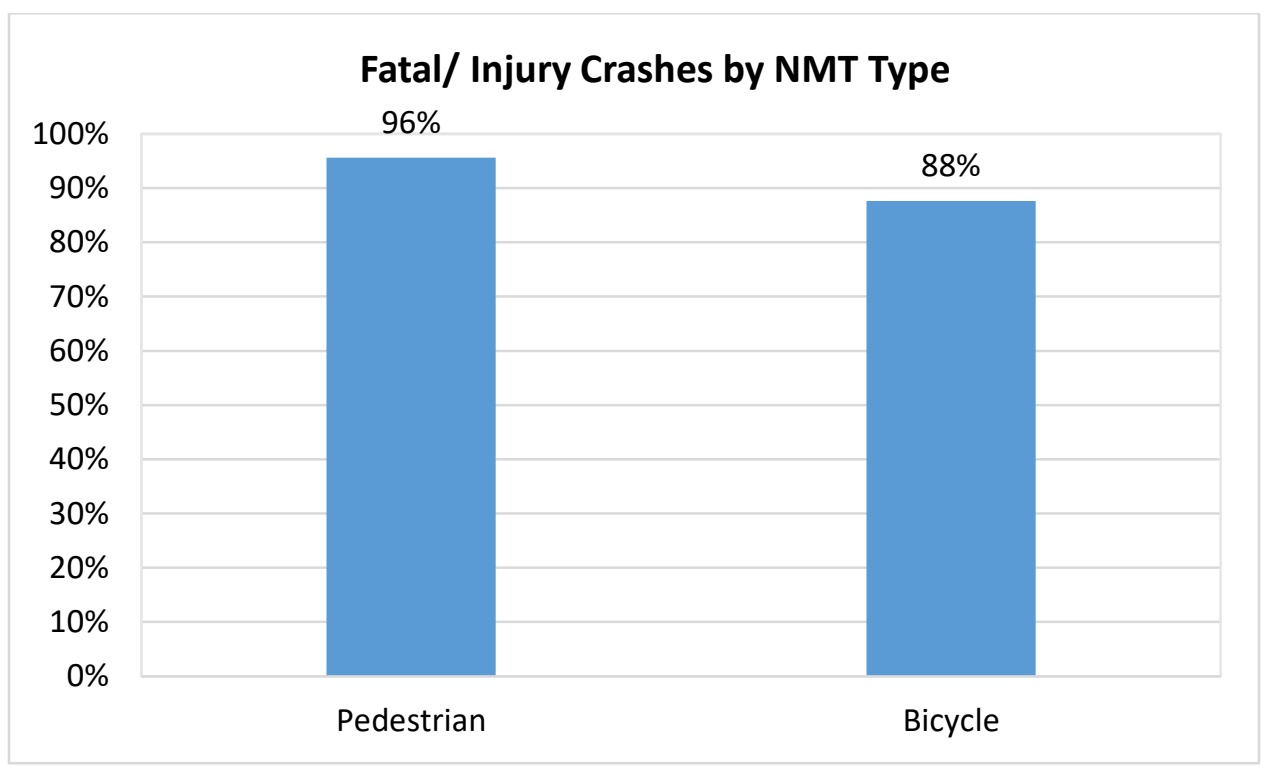

Figure 4.3 Percentage of Fatal and Injury Crashes by NMT Road User

Light condition status may have an impact on the VRU's crash severity due to visibility issues. Figure 4.4 shows that the rate of fatal and injury crashes by light condition. The parameter light condition was reduced into two major levels, that is, into daylight and nighttime due to small numbers in some of the original light condition levels. As expected, nighttime crashes lead into higher F\&I type of crashes (95\%) compared to those that 
occurred during daylight (91\%). VRUs are recommended to be extra vigilant when crossing intersections at nighttime or when visibility and sight distances are low.

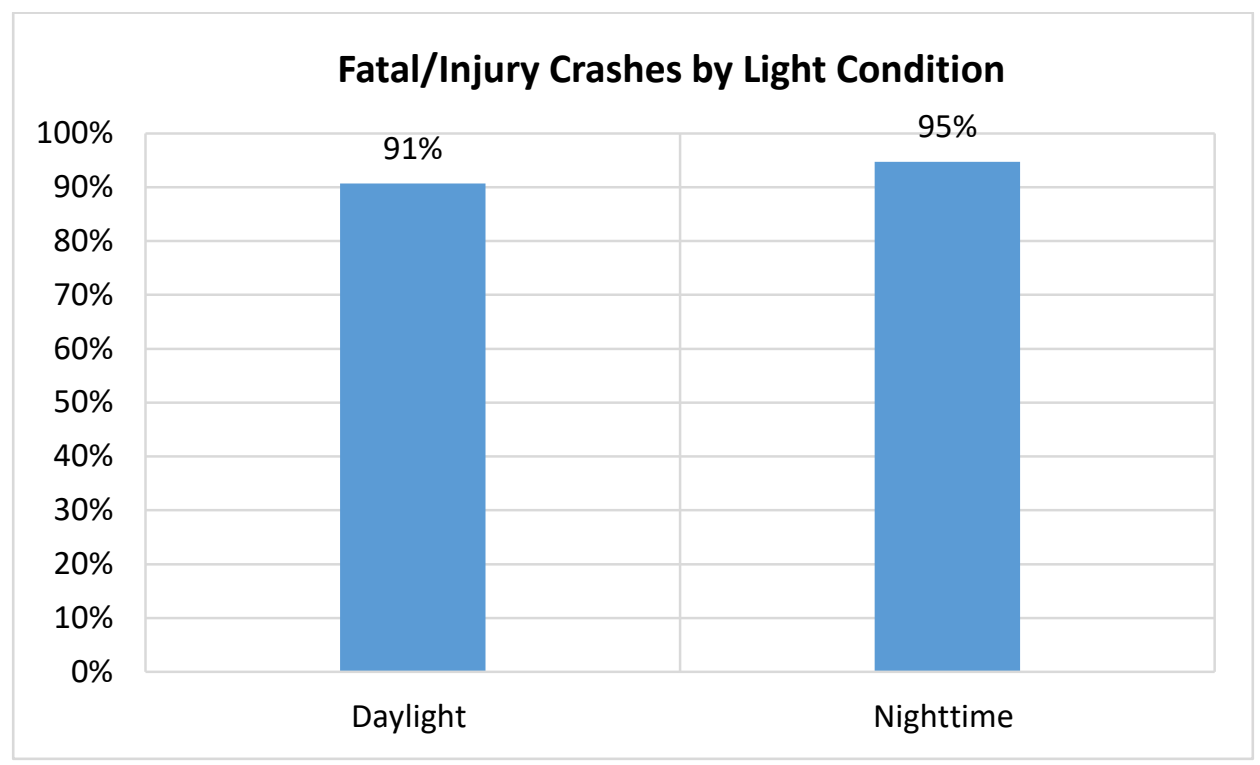

Figure 4.4 Percentage of Fatal and Injury Crashes by Light Condition

Figure 4.5 shows the percent of fatal and injury crashes during different weather conditions. The variable weather condition was reduced into three levels, that is, into clear, cloudy, and adverse condition (e.g., rain, snow, fog, severe wind, etc.). Pedestrian and bicycle collisions with motor vehicles at intersections during adverse weather conditions happened to be more likely to lead into fatal and injury crashes (93\%) compared to clear and cloudy conditions, for which both of them had a similar rate of fatal and injury crashes $(92 \%)$ 


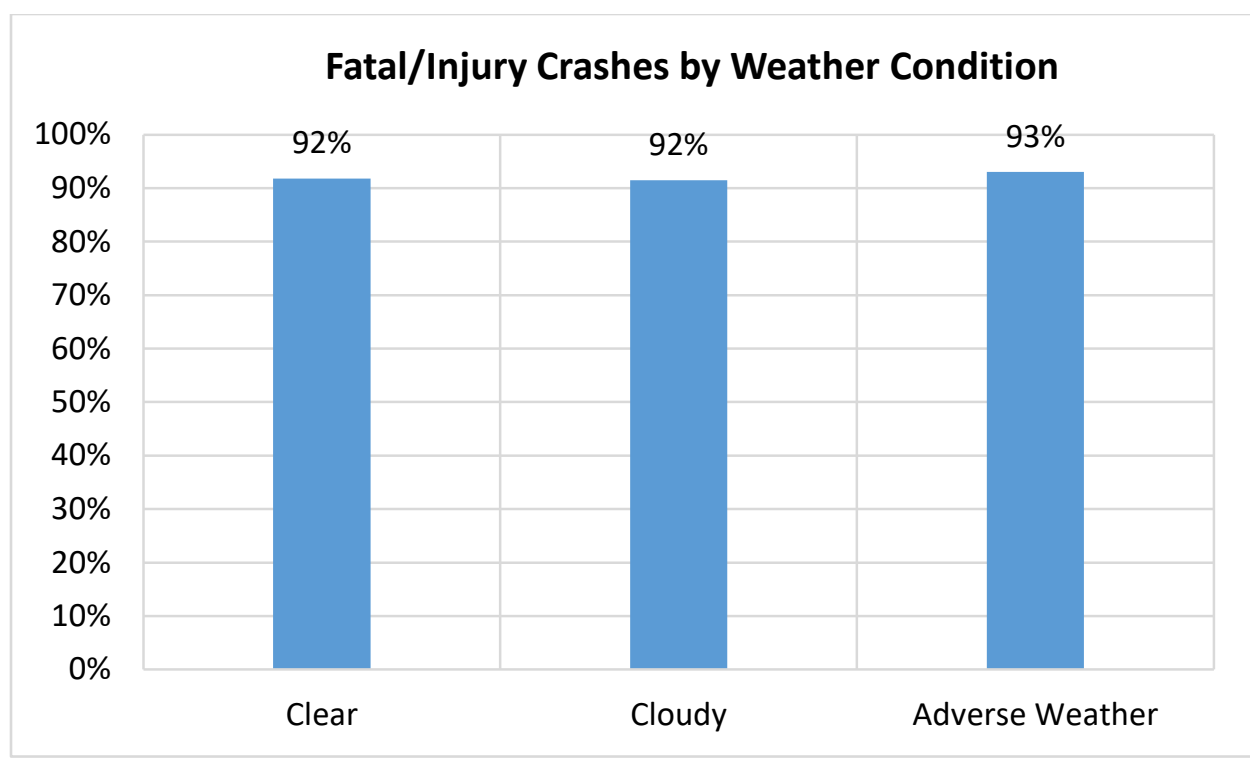

Figure 4.5 Percentage of Fatal and Injury Crashes by Weather Condition

Figure 4.6 shows percent of fatal and injury crashes by age groups considered in this study. It shows that for young NMT road users aged 30 years and below had the lowest rates of fatal and injury crashes (91\%) compared to the other age groups. The 31-64 age groups had higher rates at $93 \%$ but for the senior citizens (age 65 years and above), their crashes experienced much higher F\&I crash rates. This is a most likely expected result, as older people tend to sustain higher levels of injuries due to their fragility compared to young people even if they are involved in a similar type of crash. 


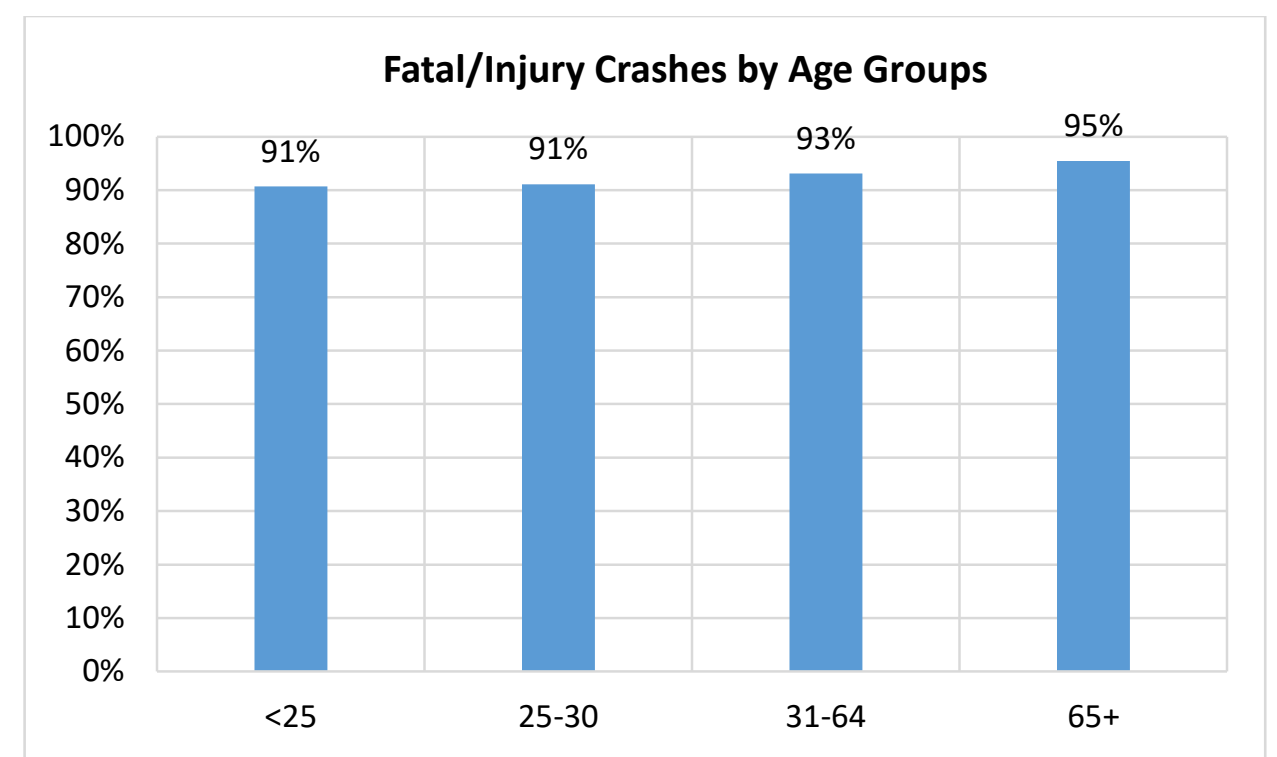

Figure 4.6 Percentage of Fatal and Injury Crashes by Age Group

In term of gender, also there was a noticeable and expected difference between male and female vulnerable road users as shown in Figure 4.7. Females received higher rates of fatal and injury crashes (95\%) compared to that of males $(90 \%)$. Female are more vulnerable than males when involved in traffic crashes.

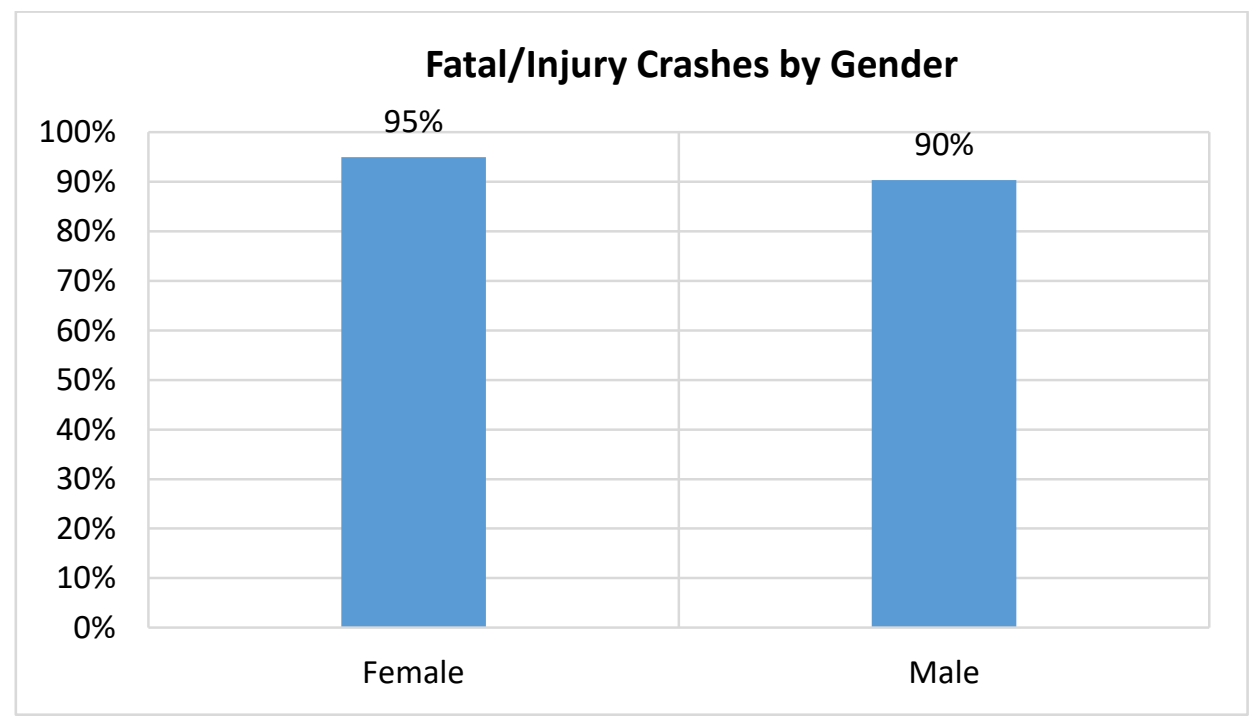

Figure 4.7 Percentage of Fatal and Injury Crashes by Gender 
Figure 4.8 shows the percent of fatal and injury crashes by roadway condition. The variable road condition was reduced into two major levels, that is, into dry and wet/adverse pavement conditions. The differences were not high between the two pavement conditions. While crashes that occurred on dry pavements had a fatal and injury rate of $92 \%$, those that occurred on wet pavements had a rate of $93 \%$, which is just a slight difference.

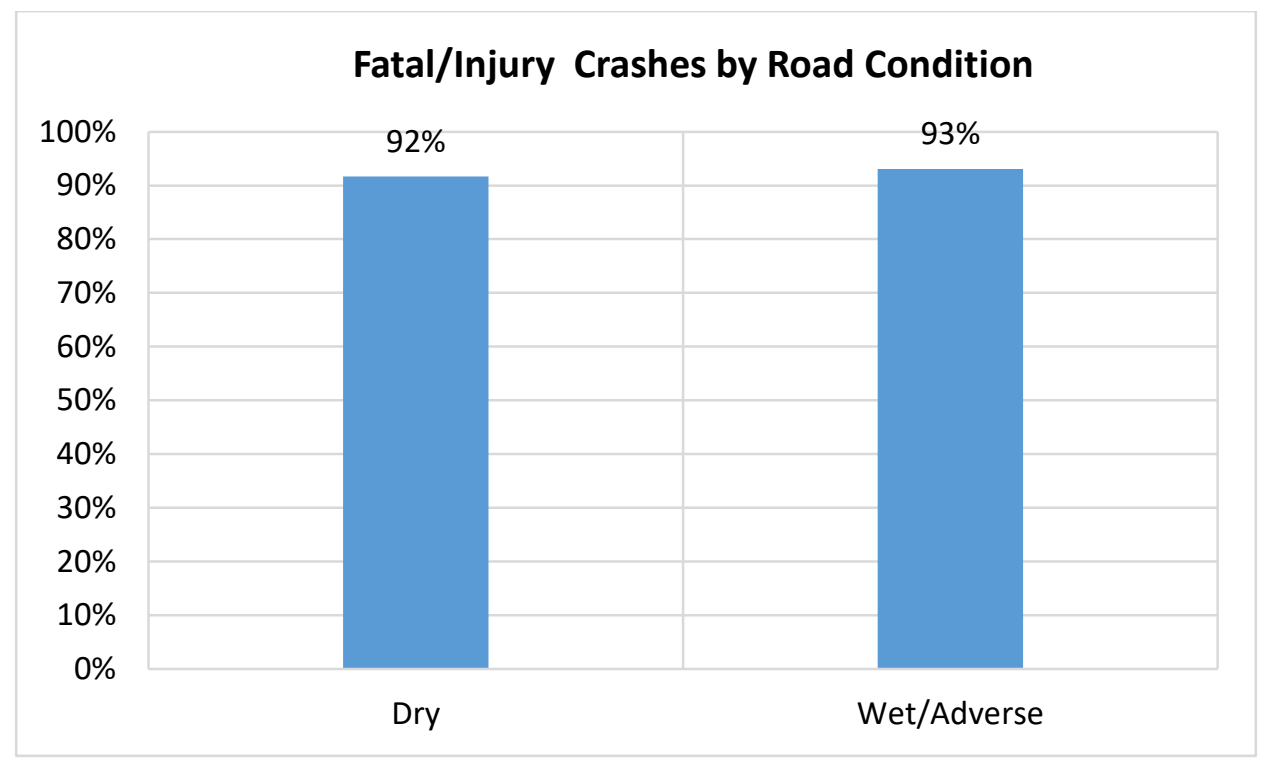

Figure 4.8 Percentage of Fatal and Injury Crashes by Road Condition

Figure 4.9 shows the percent of fatal and injury crashes by posted speed limit. The levels for the variable speed limit were reduced into two categories, that is, into speed limits less than or equal to $25 \mathrm{mph}$ and higher than $25 \mathrm{mph}$. There were no differences in the percent of fatal and injury crashes between the two posted speed limit groups considered in this study as shown in Figure 4.9. 


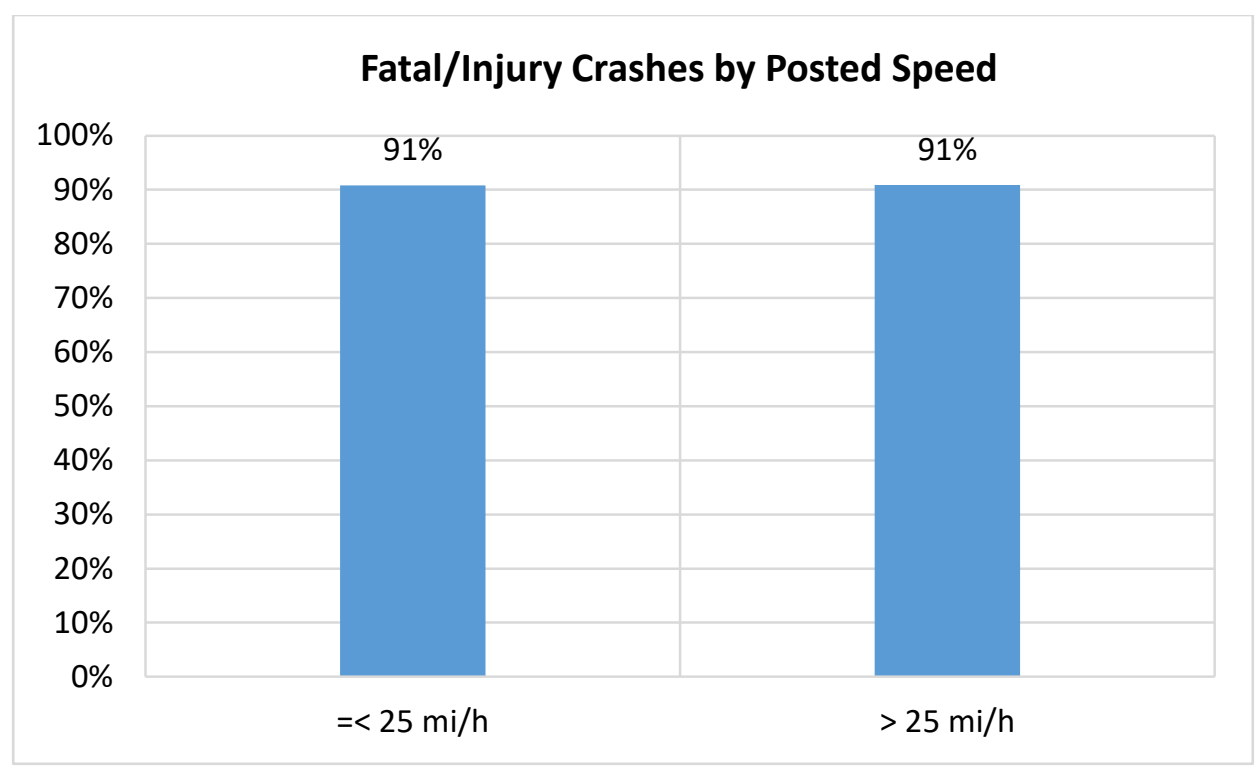

Figure 4.9 Percentage of Fatal and Injury Crashes by Posted Speed Limit

Figure 4.10 shows the percent of fatal and injury crashes by day of the week. The days in the parameter day of the week were grouped into two levels, that is, into weekdays or weekends. There was no much difference in the rates of fatal and injury crashes for the day of week grouping used in this study as evidenced in Figure 4.10. Crashes that occurred during the weekdays had a $92 \%$ fatal crash rate while those that occurred during the weekends had a fatal crash rate of $91 \%$. 


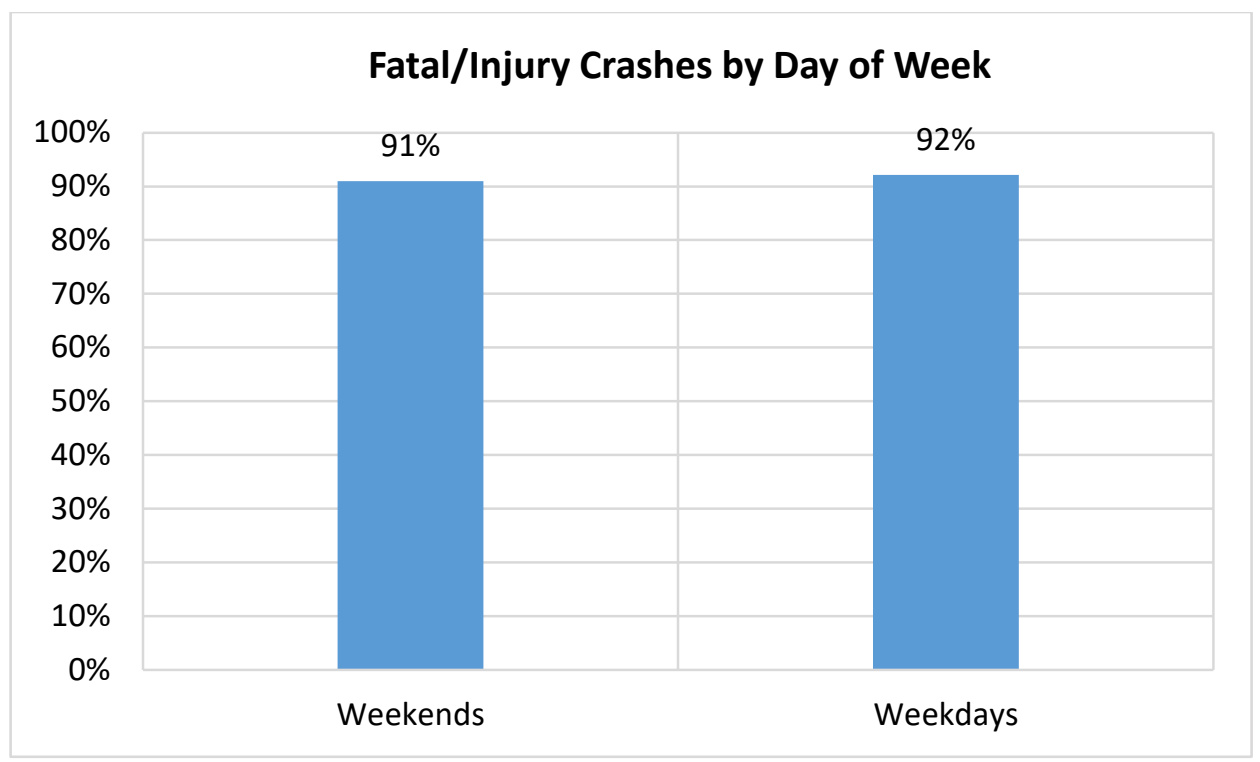

Figure 4.10 Percentage of Fatal and Injury Crashes by Day of the Week

Figure 4.11 shows the percent of pedestrian and bicycle crashes involving motor vehicles at intersections that were recorded as fatal and injury crashes by location. Crashes were divided by area type where they occurred by a broad categorization of either urban or rural locations. Figure 4.11 shows that crashes that occurred in rural locations had a slightly higher percent of fatal and injury crashes compared to those that occurred in urban areas. This is may be in part due to higher speeds typically of rural roads compared to urban roads. 


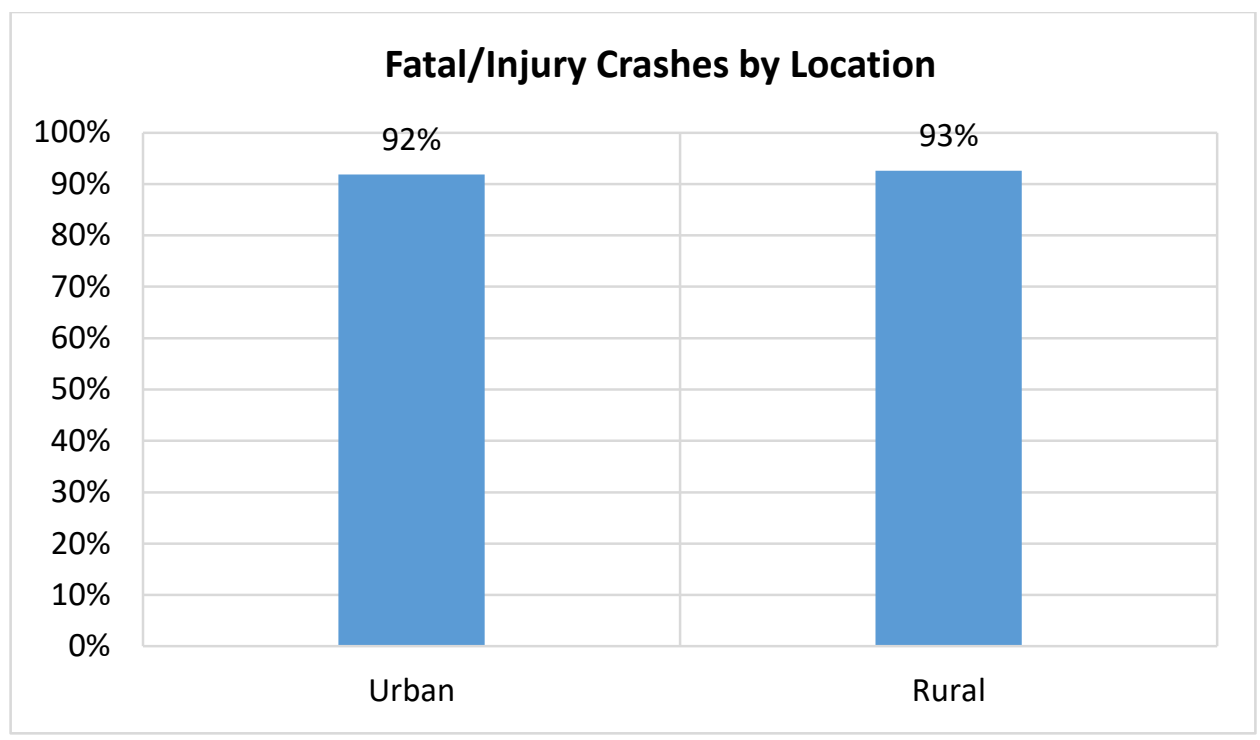

Figure 4.21 Percentage of Fatal and Injury Crashes by Location of Crash

Figure 4.12 shows the percent of fatal and injury crashes by whose error was regarded as the main cause of the crash. For crashes that were reported to be caused by non-motorized road users (pedestrians or bicyclists) had a lower percent of F\&I crashes $(90 \%)$ compared to those that were caused by motor vehicle drivers $(94 \%)$.

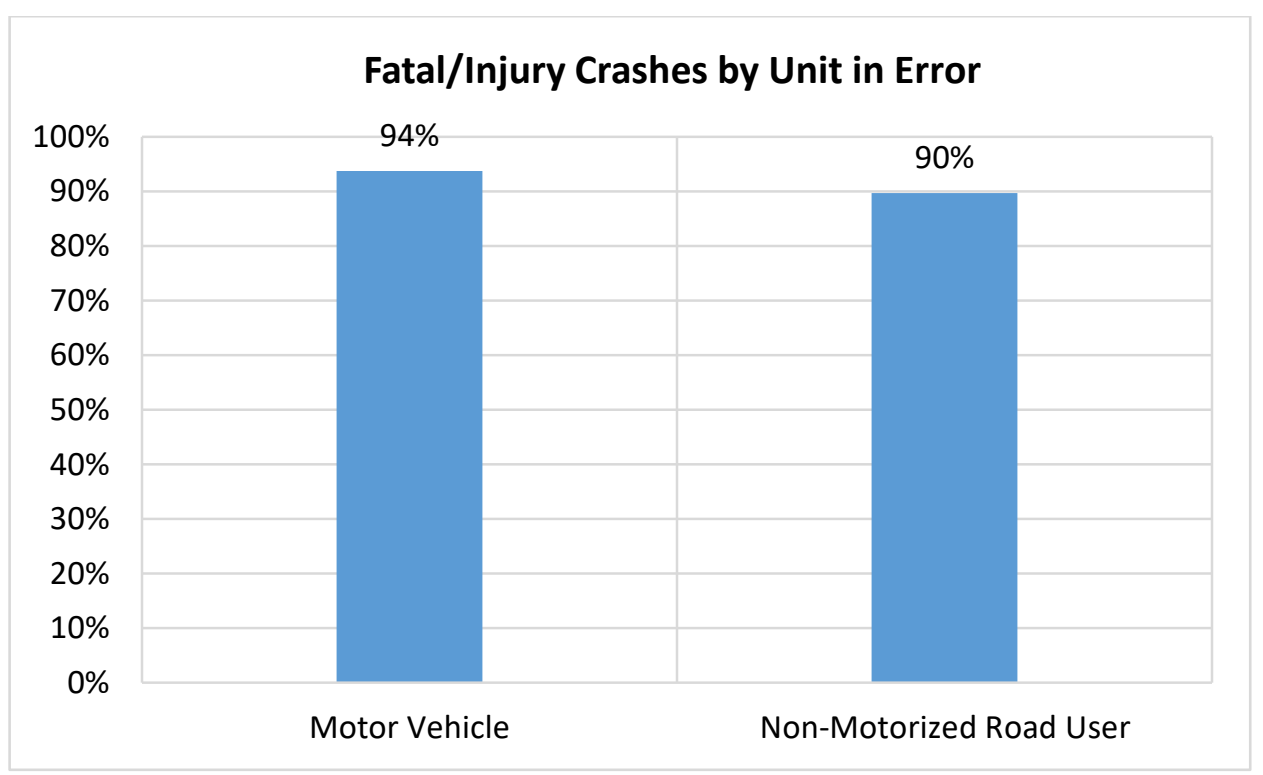

Figure 4.32 Percentage of Fatal and Injury Crashes by Unit in Error 
4.3 Binary Logistic Model Results of Crash Severity Analysis

The fourteen factors (variables) described in Chapter 3 were used to predict the crash severity of pedestrians and bicycles when struck by motor vehicles at intersections by utilizing the binary logistic regression model. The logistic stepwise selection procedure in the SAS software release 9.4 was used to produce the predictor parameter estimates and computation of odds ratios. Table 4.1 presents logistic model results only for significant factors at alpha level 0.10 (90\% confidence level) from the SAS logistic output. Out of fourteen predictor variables that were tested in the model, only five were statistically significant. Table 4.1, provides a detailed comparison of different levels (categories) for each significant predictor variable.

Table 4.1 Detail of Significant Parameters from Binary Regression Model

\begin{tabular}{|l|c|c|c|}
\hline \multicolumn{1}{|c|}{ Effect } & Odds Ratio & \multicolumn{2}{c|}{$\begin{array}{c}\text { 90\% Confidence } \\
\text { Limits }\end{array}$} \\
\hline $\begin{array}{l}\text { UNIT_IN_ERROR: Motor vehicle vs Non- } \\
\text { motorized (pedestrian/bicycle) }\end{array}$ & 0.736 & 0.602 & 0.901 \\
\hline GENDER: Male vs Female & 0.668 & 0.519 & 0.852 \\
\hline LIGHT_CONDITION: Nighttime vs Daylight & 1.482 & 1.163 & 1.906 \\
\hline $\begin{array}{l}\text { ROAD CONTOUR: Curve \& grade vs Straight \& } \\
\text { level }\end{array}$ & 1.468 & 1.092 & 2.012 \\
\hline $\begin{array}{l}\text { PEDESTRIAN_RELATED: Pedestrian vs } \\
\text { Bicycle }\end{array}$ & 2.423 & 1.923 & 3.07 \\
\hline
\end{tabular}

Results in Table 4.1 reveal that five significant variables at the $90 \%$ confidence level tested in the current study are pedestrian-related, road contour, light condition, gender, and unit in error. Figure 4.13 also depicts the same results shown in Table 4.1 in a pictorial form. The odds of a crash involving a pedestrian and a motor vehicle at an 
intersection becoming fatal or injury are 2.423 over the crash involving a bicycle given that all other variables remain constant. In other words, pedestrians are significantly more likely to result into fatal and injury compared with bicyclists.

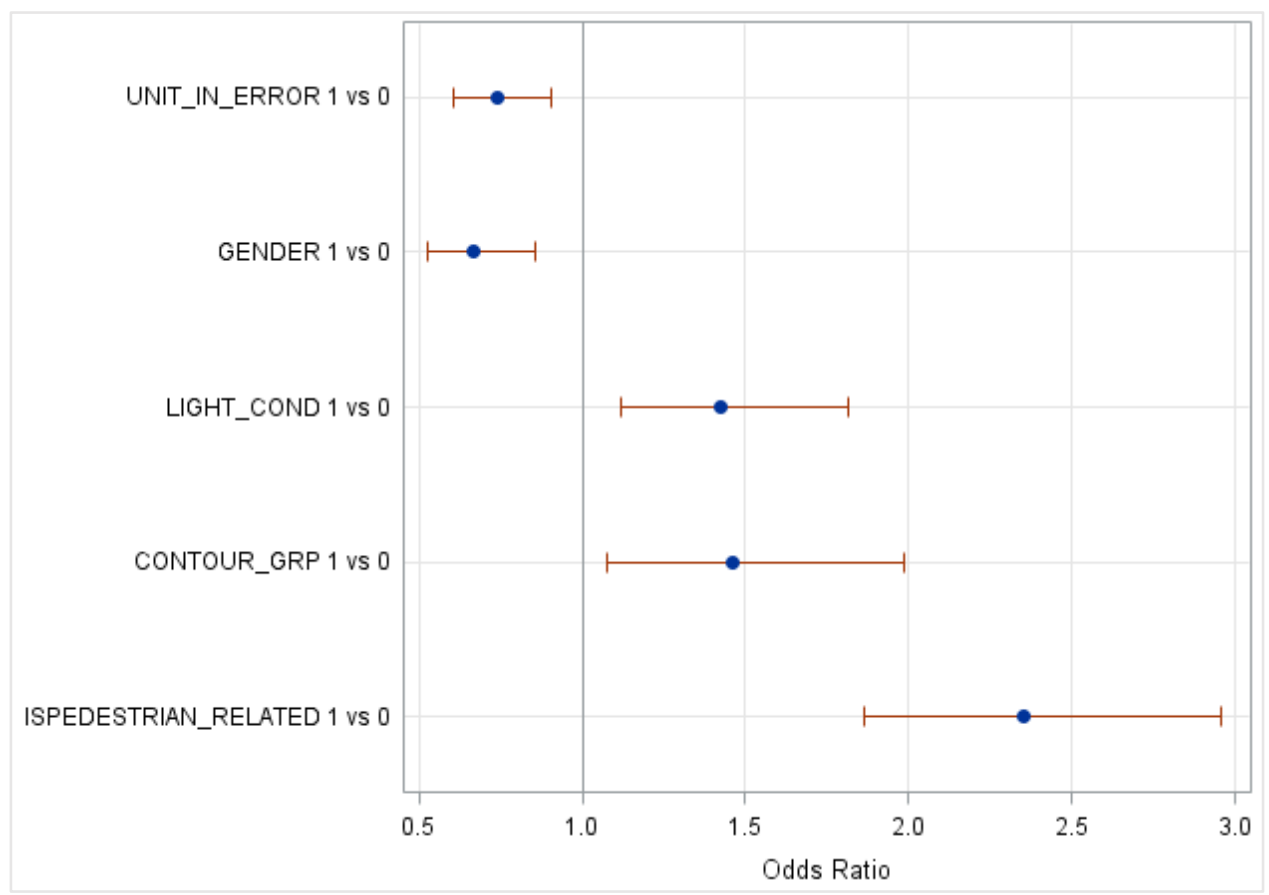

Figure 4.13 Odds Ratio with 90\% Wald Confidence Limits

Road contour is another variable that is significant in predicting bicyclist and pedestrian fatal and injury crashes. The presence of curves and/or grades increases the odds of crashes involving motor vehicles and pedestrians or bicyclists to result into fatalities or injuries. This means that intersections at locations where intersecting roads have curved and are on grades are significantly dangerous to vulnerable road users compared to those located on level and straight roads.

In addition, intersection-related crashes involving motor vehicles striking pedestrians or bicyclists have elevated likelihood of resulting into injuries or fatalities when 
they occur during nighttime when it is likely to be dark compared with during when it is daylight and visibility likely to be better. Similarly, when such crashes occur and the pedestrian or a bicyclist is a female, it increases the odds of sustaining injuries or death compare to the situation if the non-motorist is a male. Lastly, when the crash happens between a motor vehicle and a non-motorist road user, the person at fault between the two in causing the crash is significant. Results in Table 4.1 reveal that if the motor vehicle driver was at fault there is a relatively lower likelihood of injury or death to the pedestrian or bicyclist. This can be explained that when the motor vehicle driver is at fault, they try to take counter measures to evade the crash including braking and slowing down and hence lower speeds at impact. Nevertheless, if a pedestrian suddenly steps into traffic or intersection (i.e., the pedestrian/bicyclist is at fault), there is not much the driver can do, probably not able to brake quickly or slowdown in time to lead into low speed impact.

The results of the current study can be compared with other previous studies of bicycle and/or pedestrian intersection-related crashes with motor vehicles. It is noteworthy to mention that, unlike the current study that utilized a combined pedestrian and bicycle model, most studies are either pedestrian or bicycle models only. When comparing the results from the current study with a study by Lee and Abdel-Aty (2005), which analyzed vehicle-pedestrian crashes at intersections in Florida, we notice that the two studies agree in some cases but differ in some other cases especially noting that some of the investigated parameters differ between the two studies. The two studies agree that darkness lighted environment (nighttime) and gender of pedestrian (being female) increase the odds of pedestrians and bicyclists sustaining injuries or death when struck by motor vehicles at 
intersections. Alcohol involvement and location (rural/urban setups) and pedestrian were significant in Lee and Abdel-Aty (2008) study but were not in the current study.

The results from a study by Kim et al. (2007) that analyzed bicyclist injury severities in bicycle-motor vehicle crashes using data from North Carolina can be compared with the results of the current study. Although their study analyzed bicyclemotor vehicle collisions but did not concentrate on intersection crashes, one of their findings, darkness without lights (nighttime light condition) agree with current study. However, their other findings such as adverse weather, intoxication, and age were not significant enough in the current study at the $90 \%$ confidence level.

The results from a study by Moore et al. (2011), which analyzed bicyclist injury severity due to motor vehicle crashes at intersections and non-intersection locations show that horizontal curves with grades increase the injury severity of bicyclists at intersections agree with the findings of the current study. Some other factors found significant in Moore et al. (2011) study such as not wearing helmet and area of the bicycle that was struck were not tested in the current study.

Eluru et al. (2008) study that investigated injury severity determinants for pedestrians and bicyclists (non-motorists) found that light condition (darkness increases fatal and injury crashes) was significant in predicting injury severity of non-motorists, which agree with the current study. However, some of their significant factors that increase the non-motorist's injury severity such as age of individual (older persons) and posted speed limit (higher speeds) were not statistically significant in the current study. 
Based on the results of the current study, a limited number of countermeasures can be recommended due to few factors found significant. Since intersections located at locations with a combination of horizontal curves and grades were found to increase crash safety of pedestrians and bicyclists, it is recommended to check the availability of adequate stopping sight distances at such intersections. Educational campaigns with a message for motor vehicle drivers to exercise extra care and lookout for crossing pedestrians and bicyclists when turning left, right, or going straight at intersections. In addition, campaigns should target pedestrians and bicyclists to look out for motor vehicles at intersections and exercise extra care before crossing the intersections reminding them of their vulnerability due to their elevated injury severities when struck by motor vehicles.

Improving lighting at all intersections, especially where pedestrians and bicyclists are expected may improve visibility and hence reduce the occurrences of motor vehicle and non-motorist crashes at intersections. Since when non-motorists are at fault in intersection-related crashes increases the odds of their injuries and fatalities when struck by motor vehicles, these road users should be the target for education. That is, education campaigns should aim at educating citizens of their responsibilities when they are using the road as pedestrians and bicyclist; they have a role to play in traffic safety. Each individual should know who has the right-of-way at the intersection, on the crosswalk, or at zebra crossing and what is the expectation of each, the driver of motor vehicle and the non-motorist. 


\section{CHAPTER V}

\section{CONCLUSIONS AND RECOMMENDATIONS}

Vulnerable road users (VRUs) such as pedestrians and bicyclists, also known as non-motorists, are vulnerable due to lack of protection in traffic. They are even more vulnerable at inteserctions due to increased exposure and conflicts with motor vehicles whose paths have to cross each other. The main objective of this thesis study was to determine factors that contribute significantly to the crash severity of intersection-related crashes involving motor vehicles and the vulnerable road users. When a motor vehicle crashes with a non-motorist road user, the non-motorist road user sustains the higher injury levels. This is a reason why VRUs require additional attention when planning and designing roadway infrastructures. Based on the objectives of this study, a three-year crash database from January 2013 to December 2015 acquired from the Ohio Department of Public Safety was utilized for this analysis. The binary logistic regression model was applied to estimate statistically significant predictor variables that contribute in increasing bicyclist and pedestrian-related crash severity levels. This model was chosen due to its suitability in modelling ordered categorical dependent variables that are binary in nature (with two categories only). The stepwise selection logistic procedure in the SAS software release 9.4 was used to perform the analysis. 
The binary logistic regression model identified five statistically significant predictor variables out of fourteen independent variables considered in the current research. The predictors that increase crash severity of crashes involving VRUs who collide with motor vehicles at intersections are if the non-motorist is a pedestrian, and if intersection is located on horizontal curves and/or grades. In addition, if the gender of the non-motorist is a female, if light condition is dark (nighttime), and if the person at fault for the crash is a non-motorist. The other factors that are usually significant such as posted speed limits, alcohol-related, age, etc., were not significant in the current study. However, speed-related, which is also usually significant in such studies, it was not tested in the current study because the cases where speeding was involved were very few (less than 3\%) and thus on statistical point of view, it was decided to be dropped out.

Based on these results, not many countermeasures can be recommended; mainly we recommend educational campaign for both motorists and non-motorists to be extra vigilant at intersections, i.e., for motorists to look for pedestrians and bicyclists, and for non-motorists to look over for motor vehicles and be more vigilant. Since most of the crashes with severe crash severity happen at locations with horizontal curves and/or grades, there might be a problem with adequate sight distances. Therefore, on such intersections, extra care needs to be exercised from both the turning or going through motorists and road crossing non-motorists.

The current study recommends further studies to concentrate on injury severity of VRUs using the KABCO (fatal, incapacitating injury, non-incapacitating injury, possible injury, and no injury) scale. In addition, it is recommended to develop separate models for pedestrians and bicycles and compare them with a combined model of both non-motorists. 
The issue of who has the right-of-way at cross-walk at intersection may need to be studied and determine the knowledge level of road users. 


\section{REFERENCES}

Agresti, A., 2007. An Introduction to Categorical data analysis.2nd Edition. John Wiley and Sons, Inc., New York.

Almutairi, O. E. (2013). Characteristics of Injury and Fatality of Run-Off-Road Crashes on Ohio Roadways (Master's Thesis, University of Dayton).

Alqahtani, T. (2016). Investigation of Characteristics and Assessment of Crash Severity Factors Associated with Truck-Related Crashes in Ohio (Master's Thesis, University of Dayton).

Anderson, R.W.G, McLean, A.J., Farmer, M.J.B., Lee, B.H., and Brooks, C.G. (1997). Vehicle Travel Speeds and the Incidence of Fatal Pedestrian Crashes. Accident Analysis and Prevention, 29 (5), pp. 667-674.

Chen, H, Cao. L., and Logan, D.B. (2012). Analysis of Risk Factors Affecting the Severity of Intersection Crashes by Logistic Regression. Traffic Injury Prevention, 13, 300307.

Eluru, N., Bhat, C. R., \& Hensher, D. A. (2008). A mixed generalized ordered response model for examining pedestrian and bicyclist injury severity level in traffic crashes. Accident Analysis \& Prevention, 40(3), 1033-1054. 
Forsythe, M.J., and Berger, W.G. (1973) Urban Pedestrian Accident Countermeasures Experimental Evaluation. Volume II: Accident studies. PsycEXTRA Dataset. Washington DC: US Department of Transportation.

Herslund, M. and Jørgensen, N.O. (2003). Looked-but-failed-to-see-errors in Traffic. Accident Analysis and Prevention, 35(6), 885-891.

Kim, J-K., Kim, S., Ulfarsson, G.F., and Porrello, L.A. (2007). Bicyclist Injury Severity in Bicycle-Motor Vehicle Accidents Accident Analysis and Prevention, 39, 238-251.

Lee, C. and Abdel-Aty, M. (2005). Comprehensive Analysis of Vehicle-pedestrian Crashes at Intersections in Florida. Accident Analysis and Prevention, 37(4), 775-786.

Lefler, D.E. and Gabler, H.C. (2004). The Fatality and Injury Risk of Light Truck Impacts with Pedestrians in the United States. Accident Analysis and Prevention, 36, 295304

Moore, D. N., Schneider, W. H., Savolainen, P. T., \& Farzaneh, M. (2011). Mixed logit analysis of bicyclist injury severity resulting from motor vehicle crashes at intersection and non-intersection locations. Accident Analysis \& Prevention, 43(3), 621-630.

National Center for Statistics and Analysis. (2017a). Bicyclists and Other Cyclists: 2015 Data. (Traffic Safety Facts. Report No. DOT HS 812 382). Washington, DC: National Highway Traffic Safety Administration. 
National Center for Statistics and Analysis. (2017b). Pedestrians: 2015 Data. (Traffic Safety Facts. Report No. DOT HS 812 375). Washington, DC: National Highway Traffic Safety Administration.

Preusser, D. F., Leaf, W. A., Debartolo, K. B., and Blomberg, R. D. (1981). The effect of right-turn-on-red on pedestrian and bicyclist accidents: Final report. PsycEXTRA Dataset.

Retting, R.A., Nitzburg, M.S., Farmer, C.M., and Knoblauch, R.L. (2002). Field Evaluation of Two Methods for Restricting Right Turn on Red to Promote Pedestrian Safety. Institute of Transportation Engineers. ITE Journal, 72(1), 32-36.

Schepers, J.P, Kroeze, P.A., Sweers, W., and Wüst, J.C. (2011). Road Factors and BicycleMotor Vehicle Crashes at Unsignalized Priority Intersections. Accident Analysis and Prevention, 43(3), 853-861.

Sisiopiku, V. and Akin, D. (2003). Pedestrian Behaviors At and Perceptions Towards Various Pedestrian Facilities: An Examination Based on Observation and Survey Data. Transportation Research Part F: Traffic Psychology and Behaviour, 6(4), 249-274.

Stutts, J., Hunter, W., and Pein, W. (1996). Pedestrian Crash Types: 1990s Update. Transportation Research Record: Journal of the Transportation Research Board, $1538,68-74$.

Zajac, S.S. and Ivan, J.N. (2003). Factors Influencing Injury Severity of Motor VehicleCrossing Pedestrian Crashes in Rural Connecticut. Accident Analysis and Prevention, 35, 369-379. 